\title{
The Meta-Phillips Curve: Modelling U.S. Inflation in the Presence of Regime Change*
}

by

\author{
Chrystalleni Aristidou, ${ }^{\dagger}$
}

\begin{abstract}
A novel approach to modelling inflation dynamics is presented based on a set of Hybrid New-Keynesian Phillips Curves, distinguished by the regime duration and measures of real marginal cost, and combined into a meta-Phillips Curve using model averaging techniques. The analysis of US data over 1950q1-2016q1 shows that, while the importance of expectations of future inflation varies through time depending on the monetary policy regime and economic environment, future expectations make a more substantial contribution to current inflation than past inflation, and that the labour share is superior to the output gap as a measure of cyclical pressures on prices.

Keywords: Inflation, Hybrid New Keynesian Phillips Curve, Model Averaging, Structural Breaks

JEL Classification: E31, E58
\end{abstract}

\footnotetext{
${ }^{* \dagger}$ School of Economics, University of Nottingham, Nottingham, NG7 2RD, UK. E-mail: lezca@nottingham.ac.uk, tel: 00 44-1158466129.
} 


\section{Introduction}

The New-Keynesian Phillips Curve (NKPC) is a key relationship, widely adopted in macroeconomic models. Many studies that use the NKPC fail to accommodate an essential feature: instability. Given the deep structural changes the U.S. economy has gone through and the changing monetary policy, it is very likely that inflation dynamics have experienced major shifts. Besides, the Phillips Curve is an important ingredient in monetary policy analysis and, thus, it is only natural that shifts in monetary policy regimes will induce changes in the price-setting behaviour of firms. This paper contributes to literature by providing a compelling characterisation of U.S. inflation dynamics using flexible techniques that accommodate regime changes in an effective way.

There is substantial empirical evidence that the inflation process has changed over time (inter alia, Kim, Manopimoke and Nelson (2014), Davig (2016), Zhang, Osborn and Kim (2008) and Kim and Nelson (1999)). We argue that inflation dynamics are endogenously determined by recent inflation experiences and that expectations of future inflation adopt according to the underlying inflation behaviour over the recent past. In addition, it is shown that changes in inflation dynamics coincide with important monetary policy regime changes. For instance, central banks' move towards a strong anti-inflation stance in 1980s is shown to have anchored inflation expectations and altered inflation dynamics. These shifts imply that the dominance of future expectations over past inflation in determining current inflation varies across time and might explain the puzzling controversy in literature regarding which of the backwardlooking and forward-looking term provides the greatest contribution in the Hybrid NKPC. Indeed, Galí and Gertler (1999), Galí and Gertler and Lopez-Salido (2005) and Sbordone $(2002,2005)$ find that inflation inertia is a much less significant contributor 
to current inflation and conclude that forward-looking expectations are particularly reflective of the current state of inflation, while Fuhrer (1997) and Rudd and Whelan (2005, 2006) demonstrate that the purely backward-looking Phillips Curve provides a good approximation to the dynamics of inflation.

The aim of this paper is to analyse U.S. inflation dynamics and accommodate structural instability arising from regime breaks and changes in the underlying drivers of price-setting decisions in a flexible way. The analysis follows the approach of Lee, Morley and Shields (2015) who suggest combining models that are estimated over different sample periods using model averaging techniques. The paper constructs a meta-Phillips Curve, which involves estimation of a set of specific NKPCs, estimated over different sample periods, combined using Model Averaging techniques. The weights employed in combining individual Phillips Curves to obtain the "metaPhillips Curve" are determined according to the ability of the individual Phillips Curves to explain past inflation behaviour. The fact that weights change over time provides a useful and flexible structure with which we can interpret the changing inflation dynamics. The analysis shows that, despite the considerable structural instability observed, the meta-Phillips Curve provides a useful vehicle with which to explain inflation dynamics, and supports the view that forward-looking expectations play a key role in inflation determination, although the dominance of the forwardlooking term varies according to the prevailing economic environment and monetary policy in place. As we shall see, the estimated meta-Phillips Curve provides a coherent characterisation of inflation dynamics in the U.S. over the last fifty years, often matching regime changes in monetary policy and central banks' reactions to economic situations.

The remainder of this paper is as follows: Section 2 discusses how the regime uncertainty embedded in inflation dynamics is accommodated through the use of 
model averaging techniques and describes the modelling framework we use, focusing on the construction of weights. Section 3 presents the results of the estimation of the U.S. meta-Phillips Curve over the period 1959q4 - 2016q1, emphasising the phases of inflation dynamics in which expectations were more or less anchored, where antiinflationary policies were pursued more or less aggressively and when responses to the real economic activity became more or less acute. Section 4 concludes.

\section{Modelling Inflation in the Presence of Structural Change}

\subsection{Price-setting behaviour and its evolution over time}

The basic building block of our approach is based on the seminal hybrid NKPC model laid out in Galí and Getler (1999):

$$
\pi_{t}=\lambda x_{t}+\gamma_{f} E_{t}\left\{\pi_{t+1}\right\}+\gamma_{b} \pi_{t-1}
$$

where

$$
\begin{gathered}
\lambda=(1-\omega)(1-\theta)(1-\beta \theta) \phi^{-1} \\
\gamma_{f}=\beta \theta \phi^{-1}, \quad \gamma_{b}=\omega \phi^{-1}, \quad \phi=\theta+\omega[1-\theta(1-\beta)],
\end{gathered}
$$

and where $\pi_{t}$ denotes inflation, $E_{t}\left\{\pi_{t+1}\right\}$ represents inflation expectations conditional on the information up to time $t$, and $x_{t}$ is a proxy for the marginal cost (as a deviation from the steady-state). The derivation of the hybrid Phillips Curve asserts that the coefficients $\lambda, \gamma_{f}$ and $\gamma_{b}$ are functions of structural model parameters: $\theta$, which measures the degree of price stickiness; $\omega$, which reflects the fraction of backward-looking price setters; and $\beta$, the discount factor.

The structural parameters underlying the Hybrid NKPC capture propensities of the firm that relate to their pricing behaviour but which are likely to vary over time for 
at least three reasons: First, the commitment of central banks to maintain price stability and its strong anti-inflation stance can substantially influence the price-setting behaviour of firms. ${ }^{1}$ As Mishkin (2007) emphasises, with expectations of inflation well-anchored, shocks have a more transient and smaller effect so that agents are more capable of predicting the future outcomes of the variables of interest; monetary policy that brings stability would lead to a decrease in the deep parameter $\omega$ and an increase in $\gamma_{f}$, a decrease in $\gamma_{b}$ and an increase in $\lambda$. Relatedly, using Bayesian Vector Autoregressice models with drifting coefficients, Cogley and Sargent (2001) link the shifts in inflation dynamics to the evolution of the monetary policy. Similarly, Ascari and Sbordone (2014) emphasise the importance of accounting time-varying inflation trend when modelling inflation dynamics. The idea is that the coefficients in the Phillips Curve shift whenever monetary poilcy adjustments or changes in the target inflation force trend inflation to drift.

Second, firms' price setting behaviour will adopt in light of recent experiences of inflation. For example, lower and more stable inflation leads to less frequent price adjustments and higher $\theta$, with firms inclined to leave prices fixed for longer periods of time (see for example Ball, Mankiw and Romer (1988) and Mishkin (2007)). Equally, more persistent recent inflation means past inflation contains more information that is relevant for firms' pricing decisions and inflation will be more backward-looking, with higher $\omega$, in this case (see, for example, Taylor (2000)). The increase in $\omega$ due to an increase in persistence can therefore lead to a decrease in $\gamma_{f}$, an increase in $\gamma_{b}$ and a fall in $\lambda$.

Third, changes in the extent to which firms "pass through" changes in costs to prices (often known as the "pricing power" of firms) will be reflected in the deep

\footnotetext{
${ }^{1}$ For instance, Volcker-Greenspan's adoption of a proactive stance towards managing inflation has led to a greater control over inflation expectations (see Erceg and Levin (2003) and Taylor (2000)).
} 
parameters underlying the Hybrid NKPC. For example, as trade barriers decline, the increase in global competition dampens the ability of firms to increase prices so that the proportion of firms that leave prices unchanged i.e. $\theta$ increases resulting in an increase in $\gamma_{f}$, and a fall in $\gamma_{b}$ and $\lambda$. Indeed, an apparent flattening of Phillips Curves in a number of countries in recent years is attributed to the globalisation process and the reduction of pricing power of firms (Ihrig et al. (2007) and Melick and Galati $(2006))$.

\subsection{The meta-Phillips Curve and Model Averaging}

Against this backdrop, an analysis of inflation dynamics should accommodate the possibility of structural instability arising from changes in policy regime and shifts in economic conditions, especially when data span a long period. Although many studies employ formal break-detection tests (e.g. Zhang, Osborn and Kim (2008)), we argue that unless there is a clear-cut and abrupt break in price-setting behaviour, there will be uncertainty on the time span over which a given Phillips Curve describes inflation dynamics. Here we follow the approach of Lee et al. (2015) who designed a novel and flexible technique which combines different Taylor Rule specifications using model averaging techniques. Specifically, regime uncertainty can be accommodated in a "meta-Phillips Curve," constructed as a weighted average of a set of hybrid NKPC models, $M_{j T}$, each distinguished according to the sample period for which the model is relevant. The set of models characterising inflation dynamics over the period $T_{1}, \ldots, T_{n}$ is given by:

$$
M_{j T}: \pi_{t}=\lambda_{j t} x_{t}+\gamma_{f j t} E_{t}\left\{\pi_{t+1}\right\}+\gamma_{b j t} \pi_{t-1}+\varepsilon_{j t},
$$

where $x_{t}$ is the output gap as the measure of marginal cost ${ }^{2}$ and

\footnotetext{
${ }^{2}$ Amongst others, Galí and Gertler (1999), Galí et al. (2001) and Sbordone (2002) suggest that the
} 


$$
\begin{gathered}
j=j_{\min }, \ldots, j_{\max }, \\
t=T_{1}-j+1, \ldots, T_{1} \text { and } T=T_{1}, \ldots, T_{n} .
\end{gathered}
$$

The models are distinguished by the time span over which a given Phillips Curve is assumed to hold, considered here to be in operation for $j$ periods ending in period $T$. When there is a regime break, a new regime starts afresh so that in principle $j_{\min }=1$. In practice, however, we might use a minimum sample size of 16 observations $\left(j_{\min }=\right.$ 16) so that we have enough observations for estimation purposes. The maximum period for the survival of an unchanged inflation behaviour is theoretically unlimited, although changes in monetary policy regimes might suggest that, in practice, a given inflationary regime would not last longer than ten years, i.e. using quarterly data $j_{\max }=40 .{ }^{3}$ With these parameters, there are $40-16+1=25$ models that explain data at each point in time; i.e. there are 25 candidate Phillips Curve models that differ according to their relevant sample size. The first set of 25 models are estimated using data from period $T_{1}-j_{\max }+1$ and ending in period $T_{1}$. Further sets of 25 models are estimated as we roll through the sample to $T_{2}$, allowing for considerable flexibility in characterising regime change. The estimated parameters in an individual Hybrid NKPC, $M_{j T}$, are denoted by $\hat{\gamma}_{f j t}, \hat{\gamma}_{b j t}$ and $\hat{\lambda}_{j t}$.

The models $M_{j T}$ can be brought together in a "meta" model using methods based on Model Averaging techniques, so that analysis is not conditioned on a single model.

labour share is a better measure of the marginal cost, documenting that this measure incorporates both productivity and wage pressures to influence inflation. However, Rudd and Whelan (2007) and Neiss and Nelson (2005) condemn using the labour share which is countercyclical while basic economic theory suggests real marginal cost should be procyclical (see Mazumder (2010) for more evidence). Instead the use of output gap is encouraged.

${ }^{3}$ In the U.S. there have been six Federal Reserve Chairs since the mid-sixties so that, even in the absence of any other information, one might anticipate that there would be breaks every six or seven years. 
Specifically, the considerable structural uncertainty surrounding inflation dynamics is reflected by the idea that inflation observed at time $t$ could be explained by any of the 25 different models according to $(2.2)$ if we set $j_{\min }=16$ and $j_{\max }=40$. The meta-Phillips Curve accommodates regime uncertainty by using a weighted average of the model parameters in (2.2). Denoting the vector of parameters in the hybrid Phillips Curve (equation (2.2)) at time $t$ as:

$$
\boldsymbol{\zeta}_{j t}=\left(\begin{array}{c}
\lambda_{j t} \\
\gamma_{f j t} \\
\gamma_{b j t}
\end{array}\right),
$$

our aim is to compute the average of the posterior probability of the parameters of interest i.e. $\boldsymbol{\zeta}_{t}$ under each model weighted by the corresponding posterior model probabilities. The approach is motivated by the Bayesian Model Averaging formula, taken from Draper (1995) and Hoeting et. al. (1999), and given by:

$$
\operatorname{Pr}\left(\boldsymbol{\zeta}_{j t} \mid \mathbf{Z}_{t}\right)=\sum_{j=16}^{40} \operatorname{Pr}\left(\boldsymbol{\zeta}_{j t} \mid M_{j t}, \mathbf{Z}_{t}\right) \times \operatorname{Pr}\left(M_{j t} \mid \mathbf{Z}_{t}\right),
$$

noting that $\mathbf{Z}_{t}=\left(\mathbf{z}_{1}, \ldots, \mathbf{z}_{t}\right)$ represents all available information up to time $t$. Essentially, the left-hand side of (2.3), is the weighted average of the distributions of parameters in the Hybrid NKPC given the individual models. $\operatorname{Pr}\left(\boldsymbol{\zeta}_{j t} \mid M_{j t}, \mathbf{Z}_{t}\right)$ is the distribution of $\boldsymbol{\zeta}_{j t}$ on a specific model alone, while the weights $\operatorname{Pr}\left(M_{j t} \mid \mathbf{Z}_{t}\right)$ correspond to the posterior probability of model $M_{j t}$ given the data in the sample period reflecting how well model $M_{j t}$ fits the data. This Bayesian-type model averaging technique deals with structural uncertainty embedded within $\operatorname{Pr}\left(\boldsymbol{\zeta}_{j t} \mid \mathbf{Z}_{t}\right)$ by decomposing it into a weighted average of the conditional distributions (i.e. conditional on a specific model), $\operatorname{Pr}\left(\boldsymbol{\zeta}_{j t} \mid M_{j t}, \mathbf{Z}_{t}\right)$, using as weights the posterior model probabilities, $\operatorname{Pr}\left(M_{j t} \mid \mathbf{Z}_{t}\right)$. A typical Phillips Curve analysis considers the first element on the righthand side of (2.3) only, i.e. $\operatorname{Pr}\left(\boldsymbol{\zeta}_{j t} \mid M_{j t}, \mathbf{Z}_{t}\right)$, working only with a particular model, 
$\left(M^{*}\right)$, which is assumed to be true and making inferences that are based on stochastic and parameter uncertainties. $\operatorname{Pr}\left(\boldsymbol{\zeta}_{j t} \mid M^{*}, \mathbf{Z}_{t}\right)$ are computed on the basis of the individual models' Generalised Methods of Moments (GMM) estimates.

\subsubsection{The Model Weights}

Model weights are constructed according to:

$$
\begin{aligned}
\operatorname{Pr}\left(M_{j t} \mid \mathbf{Z}_{t}\right) & =\operatorname{Pr}\left(M_{j t} \mid \mathbf{Z}_{t-1}, \mathbf{z}_{t}\right) \\
& \propto \operatorname{Pr}\left(\mathbf{z}_{t} \mid M_{j t}, \mathbf{Z}_{t-1}\right) * \operatorname{Pr}\left(M_{j t} \mid \mathbf{Z}_{t-1}\right) \\
& =\operatorname{Pr}\left(\mathbf{z}_{t} \mid M_{j t}, \mathbf{Z}_{t-1}\right) * \sum_{l=16}^{40} \operatorname{Pr}\left(M_{j t}, M_{l t-1}, \mathbf{Z}_{t-1}\right) * \operatorname{Pr}\left(M_{l t-1} \mid \mathbf{Z}_{t-1}\right) .
\end{aligned}
$$

In practice, we can choose model weights so that they evolve over time, recursively updating them to reflect the extent to which they remain useful. A model's weight, $\operatorname{Pr}\left(M_{j t} \mid \mathbf{Z}_{t}\right)$, depends on:

- the probability of observing the final observation, $z_{t}$, in the sample $t-j, \ldots, t$, i.e. $\operatorname{Pr}\left(\mathbf{z}_{t} \mid M_{j t}, \mathbf{Z}_{t-1}\right)$, which, under standard normality assumptions, is proportional to the value of squared residuals at the end of the sample and

- the likelihood that the model remains relevant based on data up to $t-1$, $\operatorname{Pr}\left(M_{j t} \mid \mathbf{Z}_{t-1}\right)$. This in turn depends on:

-last period's weights, $\operatorname{Pr}\left(M_{l t-1} \mid \mathbf{Z}_{t-1}\right)$, and

-the transition probability, $\operatorname{Pr}\left(M_{j t}, M_{l t-1}, \mathbf{Z}_{t-1}\right)$. A simple structure for the transition probability is to assume there is a constant probability of a break, $\rho$, in the way inflation behaves, irrespective of inflation dynamics so far. If there is a break, inflation is assumed to enter a new regime starting again with the 
minimum sample size of 16 observations. That is,

$$
\operatorname{Pr}\left(M_{j, t} \mid M_{l t-1}, \mathbf{Z}_{t-1}\right)=\left\{\begin{array}{cc}
1-\rho & \text { if there is no break in the PC } \\
\rho & \text { if a break in the PC occurs. }
\end{array}\right.
$$

If inflation is explained by a previously estimated NKPC, i.e. there is no break, the model just gets bigger by one additional observation while updating the weights on the different models recursively from one period to the next to reflect the likelihood that the models remain relevant. Thus, the transition probability is equal to $1-\rho$. If a new NKPC now explains inflation dynamics, such that a new inflation regime is "born", then the transition probability is equal to $\rho$. Taken together, (2.4) and (2.5) dictate the models' weights in each period. The models' weights for the first set i.e. the first period are assumed to be equal across all models.

This approach can capture the effect of complicated structural changes that are hard to disentangle using conventional one-off structural break methods. The fact that model weights evolve over time allows for considerable flexibility in the way changes can take place. In particular, the approach can accommodate periods in which the responsiveness of inflation to the different factors changes both gradually from one state to another and abruptly.

The meta-Phillips Curve then consists of the individual estimated models, distinguished by the estimation period and sample size, and their weights and it is denoted by

$$
\bar{M}_{T}=\left\{M_{j t}, w_{j t} \quad \text { for } j=16, \ldots, 40 ; t=T_{1}, \ldots, T_{n}\right\}
$$

where $w_{j t}$ denotes the weight for model $M_{j t}$, i.e. $\operatorname{Pr}\left(M_{j t} \mid \mathbf{Z}_{t}\right)$. Since the estimated parameters in the individual hybrid NKPCs are given by $\hat{\gamma}_{f j t}, \hat{\gamma}_{b j t}$ and $\hat{\lambda}_{j t}$, the estimated parameter on the forward-looking term in the meta-Phillips Curve is given by 
$\bar{\gamma}_{f t}=\sum_{j=16}^{40} w_{j t} \times \hat{\gamma}_{f j t}$; the estimated parameter on the backward-looking term is given by $\bar{\gamma}_{b t}=\sum_{j=16}^{40} w_{j t} \times \hat{\gamma}_{b j t}$; the estimated parameter on the forcing variable is given by $\bar{\lambda}_{t}=\sum_{j=16}^{40} w_{j t} \times \hat{\lambda}_{j t}$, while the average sample size over which a given Hybrid NKPC holds is given by $\bar{j}_{t}=\sum_{j=16}^{40} w_{j t} \times j_{j t}$.

\section{Empirical Analysis}

\subsection{Data}

We now turn to the empirical analysis of the U.S. inflation dynamics. Our dataset consists of U.S. aggregate time series at a quarterly frequency extending from 1950q1 to 2016q1. The series have been obtained from the St. Louis Fed's FRED, Congretional Budget Office (CBO) and the Federal Reserve Bank of Philadelphia databases ${ }^{4}$. Inflation is constructed as the annualised (log) change in the Consumer Price Index (CPI), presented in figure 1. The figure demonstrates the dramatic changes in the inflation rate since the $1950 \mathrm{~s}$. The figure suggests that there might have been significant structural breaks in the inflation process with periods of high and highly volatile inflation in which the behaviour of price-setting is likely to have changed.

The output gap is constructed based on CBO's measure of potential GDP. The trend needed to construct the business sector labour share gap, which enters the instrument set, is based on the Hodrick-Prescott filter with smoothing parameter equal to 10000 in order to remain consistent with Mavroeidis et al. (2014). ${ }^{5}$ Wage inflation

\footnotetext{
${ }^{4}$ All data transformations closely follow the suggestions of Mavroeidis et al. (2014) as presented in their online supplement on http://www.aeaweb.org/jel/app/mar14_Mav_doc.zip.

${ }^{5}$ As part of a robustness check, the standard quarterly HP smoothing parameter of 1600, has also been used delivering identical results. It should be noted that the results remain robust to alternative definitions of the labour share gap such as the deviation of labour share from its mean
} 
is the change in the (log) of business sector hourly compensation. Survey forecasts have been used to address the weak instruments problem (see next sub-section) and inlcude the mean growth rate of CPI from the Livingston Survey $(1950 q 1-1981 q 4)$ and implied inflation forecasts based on the mean CPI from the Survey of Professional Forecasters (SPF) $(1982 Q 1-2016 q 1) .{ }^{6}$

\subsection{The weak instruments problem}

It is now widely acknowledged that there is a profound weak instruments problem associated with GMM estimation of the hybrid NKPC inflation model (see for example Nason and Smith (2008) and Mavroeidis (2005)). The problem is exacerbated, and estimates become even more unreliable, when the NKPC is flat and inflation is driven only by cost-push shocks. If such shocks are unpredictable, no relevant predetermined instruments exist and the coefficient on expected inflation becomes unidentified.

Mavroeidis et al. (2014) show that one type of specification that is better identified uses observable inflation forecasts as proxies for inflation expectations. ${ }^{7}$ Following the survey approach, the mathematical expectation of inflation, $E_{t}\left\{\pi_{t+1}\right\}$ in (2.1) is replaced by direct measures of expectations, $\pi_{t+1 \mid t-1}^{e}$ which denote the one-step-ahead

as suggested by Galí and Gertler (1999).

${ }^{6}$ Mean CPI from the SPF becomes available in 1981q3. In practise, since the estimation of the hybrid NKPC requires two lags of the survey forecasts to be used as instruments, analysis based on SPF forecasts begins in $1982 q 1$. In order to extend the sample, data is augmented with CPI inflation forecasts from the Livingston Survey starting from $1950 q 1$ and ending in $1982 q 1$, when the SPF forecasts take over.

${ }^{7}$ As Mavroeidis et al. (2014) demonstrate, the heteroskedasticity and autocorrelation robust first stage F statistic of Montiel Olea and Pflueger (2013) gets much bigger when survey expectations are used, particularly when instrument set includes lagged survey forecasts, indicating that the weak instruments problem is significantly alleviated by the use of surveys. 
survey forecast of inflation formed at time $t-1 .^{8}$ Mavroeidis et al. (2014) suggest using $\pi_{t+1 \mid t-1}^{e}$ instead of $\pi_{t+1 \mid t}^{e}$, which reflects the one-step ahead inflation expectation formed at time $t$, since $\pi_{t+1 \mid t-1}^{e}$ is certainly predetermined and not measured within the quarter. The fact that surveys forecasts contain information about the future beyond the information incorporated in most recent data makes them ideal proxies of the private sector's inflation expectations. ${ }^{10}$

Following the suggestions of Zhang et al. (2009) and Mavroeidis et al. (2014), survey data are treated as endogenous. The instrument set consists of predetermined variables and includes four lags of inflation, two lags of survey forecasts, two lags of the labour share, two lags of the output gap and two lags of the wage inflation. ${ }^{11}$ Here a parsimonious instrument set is used to avoid the potential estimation bias arising in small samples when there are too many over-identifying restrictions (Staiger and

\footnotetext{
${ }^{8}$ Since this paper uses quarterly data, $\pi_{t+1 \mid t-1}^{e}$, captures the expectation of inflation one quarter ahead, as reflected in Livingston survey (until 1981q4) and SPF (post 1981q4).

${ }^{9}$ This paper uses short-term one-quarter ahead inflation forecasts but recent papers also consider long-term forecast horizons which reflect a central bank's inflation goals (see for example Fuhrer (2011)). The SPF data on expected inflation over the next ten years become available in 1991. As part of a robustness check, the meta technique discussed in this paper was conducted with post-1991 data, using long run inflation expectations and the results remained unchanged.

${ }^{10}$ Inter alia, Faust and Wright (2013) and Ang, Bekaert, and Wei (2007) demonstrate that SPF inflation forecasts exhibit superior forecasting performance than model-based forecasts, suggesting that surveys reflect information that is useful for the joint data generating process of realised and anticipated inflation (Mertens and Nason (2015)).

${ }^{11}$ To gauge the extent to which the meta approach is sensitive to the instrument set, analysis was re-conducted using larger and smaller instrument sets. This robustness check has shown that the approach is invariant to the exact variables that enter the instrument set, with the analysis resulting in the same inferences about the existence and location of inflation regimes.
} 
Stock (1987)). Heteroskedasticity and Autocorrelation Consistent (HAC) Newy-West type standard errors are computed with lag truncation parameter equal to 2.

\subsection{Results}

Our characterisation of U.S. inflation is based on our estimated meta-Phillips Curve, obtained as a weighted average of the various models described in (2.2), using the U.S. data for the period 1950q1-2016q1. Given our setup, the first set of 25 Phillips Curves that were estimated relate to the sample window of 40 observation from $1950 q 1$ $1959 q 4$, estimating one Phillips curve over the whole period, then one Phillips curve over the period $1950 q 2-1959 q 4$, and so on, finishing with one model estimated over the minimum sample size of 16 observations, i.e. over $1956 q 1-1959 q 4$ and weights were calculated for each of these 25 models according to (2.4) and (2.5). The second set of 25 Phillips Curves relates to the 40 observations from $1950 q 2-1960 q 1$ and so on, moving recursively through the dataset.

The nature of inflation dynamics based on the meta-Phillips Curve analysis is reflected in figures $2 \mathrm{a}-2 \mathrm{~d}$ which show the weighted average sample size, estimated parameters and weights. The evolution of the average coefficient on the forwardlooking term is a mirror image of the evolution of the average coefficient on the backward-looking term, a by-product of the fact that the sum of the two coefficients is restricted to unity. Confidence bands are plotted to show the precision of the estimated statistics and are obtained through stochastic simulation. ${ }^{12}$

\footnotetext{
${ }^{12}$ The construction of confidence bands for the meta-Phillips Curve is based on simulation methods in which 10,000 alternative "histories" of the inflation series are generated according to (2.2). The simulation takes into account that at each point in time there is a constant probability of break in the way inflation behaves. For each simulated series, the procedure described to estimate the metaPhillips Curve was implemented and distributions of average sample length and average coefficients were obtained. The confidence intervals illustrate the range covered by two standard deviations of
} 


\subsubsection{The importance of structural breaks}

A summary of the underlying estimated relations plotted in figures $2 \mathrm{a}-2 \mathrm{~d}$ over the period $1959 q 4-2016 q 1$ can be reflected by the sample median values of the metaPhillips Curve's weighted average coefficients $\bar{\gamma}_{f t}, \bar{\gamma}_{b t}$ and $\bar{\lambda}_{t}$ :

$$
\pi_{t}=0.04 x_{t}+0.83 E_{t}\left\{\pi_{t+1}\right\}+0.17 \pi_{t-1}+\hat{\varepsilon}_{t}
$$

where figures in parentheses correspond to one standard deviation of the values of $\bar{\gamma}_{f t}, \bar{\gamma}_{b t}$ and $\bar{\lambda}_{t}$ over the sample. The average counterpart of equation (3.7) involves computing the sample averages of the meta-Phillips Curve's weighted average coefficients. Accordingly, the average meta-Phillips Curve is summarised as follows:

$$
\pi_{t}=0.05 x_{t}+0.73 E_{t}\left\{\pi_{t+1}\right\}+0.27 \pi_{t-1}+\hat{\varepsilon}_{t}
$$

Equations (3.7) and (3.8) reveal a number of insights: First, the fact that the median value of the weighted average coefficient on the forward-looking term is bigger than the mean value demonstrates that the weighted average coefficients are left skewed with the bulk of coefficients located at the high end of the distribution. This suggests that in most cases, the weighted average coefficients on the forward looking term are significantly high. The results are in line with findings of Galí and Gertler (1999) who demonstrate that the forward looking behaviour is more dominant than backwardlooking behaviour with the estimate of the coefficient on expected inflation lying well these distributions. Further details on the simulation method can be provided by the author upon request. 
above the coefficient on lagged inflation. As we will later see, with few exceptions, the weighted average coefficient on the forward-looking term was larger than the one on the backward-looking term, suggesting that even when structural breaks are taken into consideration, expectations are particularly important in determining current inflation.

Figure 2e shows the evolution of the p-value from the test that the average coefficient on the forward looking term is equal to the average coefficient on the backward looking term, against the alternative that the first is larger than the latter. The statistic is based on the difference between the forward and backward looking parameters in each of the 25 models at each point it time. Treating this difference as independent observations of a variable, this statistic gives an indication of the size and statistical significance of the difference between the average coefficients on the forward and backward looking terms. Having 25 models at time $T$, the test considers the null hypothesis that the mean of these 25 differences is significantly different to zero using a standard t test, assuming the variable is normally distributed. Figure 2e reveals that, with few exceptions, the test rejects the null hypothesis and concludes that, on average, the coefficient on the forward-looking term is significantly larger than that on the backward looking terms at $1 \%$ significance level. The only two periods where the average coefficient on the forward looking term is not significantly bigger than that on the backward looking term are $1959 q 4-1961 q 4$ and $1969 q 4-1980 q 4$. As it is shown later on, the second period coincides with the high inflation episodes that de-anchored inflation expectations.

In contrast to Russell et al. (2010) who show that once structural breaks have been addressed, expectations in the Hybrid NKPC become insignificant, we find that expectations play a dominant role in inflation dynamics, albeit at different degrees, depending on the prevailing economic conditions and the monetary policy in place. 
Second, the coefficient on the forcing variable is positive, indicating that the effect of marginal cost on inflation is important. To validate the statistical significance of this result, a t-test was performed to test the null hypothesis that the mean of the weighted-average coefficients on the forcing term across the sample is equal to zero against a two-sided alternative. The test statistic is considerably higher than the critical value from a t-distribution with 225 degrees of freedom at the $5 \%$ significance level, and therefore the null hypothesis is rejected. This result is in line with the priori theory that predicts that the slope coefficient on the real economic activity measure should be positive and significant (Galí and Gertler (1999, p.207)).

Third, the large standard deviations demonstrate the considerable structural instability embedded in inflation dynamics, highlighting the need to accommodate structural breaks in the Phillips Curve relationship.

In the event, of course, the sample average coefficients do not convey the full detail of the meta model and the time variation in the parameters of figures $2 \mathrm{~b}-2 \mathrm{~d}$. On the contrary, the patterns in the time-varying coefficients of the meta-Phillips Curve can be interestingly be explored by running a simple OLS regression of the time-varying $\bar{\gamma}_{b t}$ on factors that are thought to affect its level. As outlined in section 2.1 , inflation dynamics are likely to be affected by the monetary policy in place and recent inflation experiences. Accordingly, we regress $\bar{\gamma}_{b t}$ on lagged inflation, $\pi_{t-1}$, the variance of inflation rates over the past 12 quarters, $v_{t}$, and dummies reflecting different exogenous monetary policy regimes as distinguished by Lee et al. (2015) who use the meta-technique on the Taylor rule relationship. The following regression was therefore estimated over $1959 q 4-2016 q 1$ :

$$
\bar{\gamma}_{b t}=a+\beta \pi_{t-1}+\gamma v_{t}+\sum_{i=1}^{7} \delta_{i} D_{t}^{i}+e_{t},
$$

where $D_{t}^{i}$ is an indicator function corresponding to the $i^{t h}$ monetary policy regime as 
identified by Lee et al. (2015). In particular, the regression includes seven monetary policy regimes: Burns phase $(1970 q 1$ - 1978q1), Miller phase $(1978 q 2$ - 1979q3), Volcker/early-Greenspan phase $(1979 q 4$ - 1993q4), mid-Greenspan phase (1994q1 $1999 q 2)$, late-Greenspan phase $(1999 q 3$ - 2005q4), Bernanke phase $(2006 q 1-2013 q 4)$ and Yellen phase $(2014 q 1-2016 q 1)^{13}$. The monetary policy regime under Martins (extending from $1951 q 2-1969 q 4$ ) is the base group.

The results presented in table 1 clearly validate the theoretical assumptions laid out in section 2.1 and show that the monetary policy regime in place, as well as recent inflation experiences, affect the weighted average coefficient on the dynamic terms in the meta-Phillips Curve. In particular, results confirm that high and highly volatile inflation over the recent past leads to more frequent price adjustments, a lower $\theta$ and therefore significantly higher $\bar{\gamma}_{b t}$. In addition, it appears that the monetary policy in place influences the proportion on price-setters that are forward-looking, affecting inflation dynamics accordingly. With the exception of late Greenspan's monetary policy regime, it is shown that $\bar{\gamma}_{b t}$ was, on average, different in all other policy regimes when compared to Martin's policy regime and the difference is statistically significant at least at the $5 \%$ significance level. For instance, table 1 shows that the weighted average coefficient on the backward-looking term was significantly higher during Burns' and Miller's chairmanship compared to Martin's monetary policy regime. This result is not surprising given that the $1970 \mathrm{~s}$ decade was marked by the occurrence of unprecedented inflation episodes that forced firms into more frequent price adjustments. Accordingly, the weighted average coefficient on the backward-looking term

\footnotetext{
${ }^{13}$ Lee et al. (2015) present results of the U.S. meta-Taylor rule over the period 1972q1-2008q4, and distinguish the six monetary policy regimes ranging from Burns' to Bernanke's Chairmanships. Since our meta-Phillips Curve analysis extends over 1959q4- 2016q1, we consider one additional regime at the start and one at the end of the sample (Martin's and Yellen's policy regimes respectively).
} 
was significantly lower during Volcker's big disinflation monetary regime compared to Martin's regime. The results emphasise that the monetary policy in place affects the size of the Phillips Curve's parameters to a great extent.

\subsubsection{The eleven inflation regimes}

Continuity in inflation regimes is characterised by a rising average sample size in figure 2a. On the contrary, a sharp decline in the average sample size is a signal that inflation dynamics changed at that time. Figure 2a suggests that inflation dynamics can be usefully grouped into eleven regimes as listed below. Associated inflation experiences and summary coefficients are presented in table 2 .

Phase 1: Bretton Woods I This was a period of low inflation, attributed to the stability established under the fixed exchange rate system. The monetary policy mechanism in place was automatic: Signs of overheated aggregate demand that threatened to accelerate inflation and undermine the country's competitiveness were promptly addressed by triggering a strong tightening policy. The Fed's commitment to maintain price stability reinforced its credibility and anchored inflation expectations. The fact that any shock had only transient effects meant that firms were more capable to predict the future prospects of inflation, so that the fraction of the backward-looking firms, $\omega$, was small. As shown in figure $2 \mathrm{~b}, \bar{\gamma}_{f t}$ exhibits a rising path, suggesting that the first inflation regime could be described by a purely forward-looking NKPC. The weighted average coefficient on the forcing variable over this period is shown to have steadily decreased towards zero as shown in figure $2 \mathrm{~d}$.

Phase 2: Bretton Woods II In the second inflation regime, inflation doubled and became much more volatile as conveyed by table 2. Bordo and Eichengreen (2013) emphasise that in 1963, there has been an important perceptual shift in the assumed responsibilities of the Fed that considered itself free to pursue goals other 
than dollar stabilisation, undermining the importance of controlling inflation. Effectively, policymakers placed high importance on stabilising the real economic activity and paid much less attention to price stability, unmooring inflation expectations (Orphanides and Williams (2012)). The loss of Federal Reserve Bank's credibility meant that firms became less forward-looking, reflected by the drop in $\bar{\gamma}_{f t}$ from 0.994 in the early quarters of the second regime to 0.472 by the end of the regime. Table 2 shows that average $\bar{\lambda}_{t}$ remained stable just above zero.

Phase 3: The Great Inflation The third regime, (1970q1 - 1973q4), was marked by unusual economic turmoil. The collapse of the Bretton Woods system plagued inflation expectations while the first oil price shock of the seventies brought inflation to unprecedentedly high levels. The Great Inflation forced firms into more frequent price adjustments, causing $\theta$ to drop significantly. This change in the deep parameter can explain why the coefficient on the forward-looking term in the hybrid NKPC, $\bar{\gamma}_{f t}$, exhibited a downward path, while the weighted average coefficient on the forcing variable, $\bar{\lambda}_{t}$, increased. Table 4.2 validates the argument since average $\bar{\gamma}_{f t}$ almost halved compared to the previous regime.

\section{Phase 4: The Energy Crisis}

The incidence of the second oil price shock marked the fourth inflation regime. Inflation rate reached double digit values forcing firms into more frequent price adjustments. The high inflation episodes can therefore explain why $\bar{\gamma}_{f t}$ reached its minimum value just above zero over this inflation regime. A purely backward-looking Phillips Curve provides a good approximation to inflation dynamics in this regime. This is in accordance with Zhang et al. (2008) who found that forward-looking behaviour played a very small role during the volatile inflation period $1968-1981$. The substantial decrease in the fraction of firms that left their prices unchanged is also reflected by the rising weighted average coefficient on the forcing varaible, $\bar{\lambda}_{t}$, that increased 
from zero in $1974 q 4$ to 0.16 in $1982 q 1$.

Phase 5: The Big Disinflation The first half of the eighties remained in history as the Big Disinflation period. By the end of this period, Volcker managed to bring inflation down substantially. In contrast to policies in the previous years, Volcker's programme involved a proactive stance towards controlling inflation. The meta-approach has successfully identified this major shift with $\bar{\gamma}_{f t}$ increasing to around 0.78 on average during Volcker years. The average coefficient on the forcing variable almost doubled on average compared to the previous regime as shown in table 2 .

Phase 6: The Onset of Great Moderation The onset of the Great Moderation was marked by reduced output volatility while the Federal Reserve Bank began to regain its credibility after inflation was tamed and greater transparency was established. These developments allowed firms to become more forward-looking, reflected by the high values of $\bar{\gamma}_{f t}$ during this inflation regime. After a drop at the very start of the new regime, $\bar{\lambda}_{t}$ is rising, possibly due to the decline in the proportion of backward-looking firms, $\omega$.

Phase 7: Dot.com Boom Despite the economic boom attributed to the dot.com bubble, inflation was tamed in the fear of overheating. As shown in table 2, average inflation remained low and very stable. Accordingly, average $\bar{\gamma}_{f t}$, climbed to 0.9 as shown in table 2 . The weighted average coefficient on the forcing term remained relatively stable over this regime.

Phase 8: The Burst of the Bubble This phase is characterised by major developments in the U.S. economy, marked by the outbreak of the dot.com bubble in early 2000s. The weighted average coefficient on the forward-looking term, $\bar{\gamma}_{f t}$, dropped substantially from 0.994 in $1999 q 1$ to 0.586 in $2001 q 3$, reflecting the negative outlook for the economy. $\bar{\lambda}_{t}$ exhibited a modest rise but remained mostly below 0.05 .

Phase 9: The Housing Boom After the burst of the dot.com bubble in early 
2000s, the U.S. economy has experienced a major housing boom that resulted in widespread mortgage lending and high consumer indebtedness. Agent's widespread confidence meant that the fraction of backward-looking firms, $\omega$, decreased substantially, providing an explanation for the abrupt rise in $\bar{\gamma}_{f t} . \bar{\lambda}_{t}$ evolved erratically over this period, fluctuating around 0.025 over this regime before jumping to 0.3 by the end of the regime.

\section{Phase 10: The Financial Crisis and The Great Recession}

This inflation regime was characterised by high uncertainty due to the outbreak of the global financial crisis and a series of bank and business failures. High uncertainty, in combination with fears of uncontrolled budget deficits, de-anchored inflation expectations and brought unrest among price-setters, consumers and investors. While the Federal Reserve Bank intervened through quantitative easing, confidence remained plagued due to the prolonged recession and the fact that the interest rate remained stuck to the lower bound for a protracted period of time. It is therefore not surprising that $\bar{\gamma}_{f t}$ experienced a sharp decline for a long period after $2009 q 1$.

Another important change is the well-documented flattening of the Phillips Curve,

as seen by the steady drop in the forcing variable coefficient, $\bar{\lambda}_{t}$. On average, the weighted average coefficient on the forcing variable has experienced a noticeable drop since the early eighties (with the exception of the peak in 2008q4) but the decline has become even more pronounced after 2009. Over this inflation regime, the weighted average coefficient on the forcing variable declines steadily and reaches negative values, although confidence bands include positive values. Blanchard and Galí (2007) attribute the flattening of the Phillips Curve to globalisation and the reduction in the pass-through of oil prices to prices charged to consumers. The decrease in firms' pricing power and global competition results in more firms leaving their prices unchanged ( $\theta$ increases). Other authors, like Roberts (2006) and Borio and Filardo (2007) and 
Musso et al.(2009) indentify that the recent flattening of the Phillips Curve can also be attributed to the monetary policy in place.

Phase 11: Slow recovery The meta-approach has identified that the last five quarters in the sample consitute a separate inflation regime (see figure 2a). Although the duration of this last regime is very small, a modest increase in $\bar{\gamma}_{f t}$ and $\bar{\lambda}_{t}$ can be observed, reflecting some early signs of recovery after the Great Recession.

\section{Conclusion}

This paper exploits model averaging techniques in order to characterise U.S. inflation dynamics since the $1960 \mathrm{~s}$. Model averaging techniques are employed so that the modeller can overcome the regime uncertainty related to changing monetary policies and economic conditions. Our findings are twofold: First, we find that the meta-Phillips Curve provides a flexible but compelling characterisation of inflation dynamics in the United States over the last fifty years with no single Phillips Curve dominating at any point in time. The combined Phillips Curve captures important shifts in the conduct of monetary policy and highlights key changes in inflation dynamics. The eleven inflation regimes, identified by the meta-approach, reflect eminent developments ranging from the collapse of the Bretton Woods System, the oil-price shocks of the 1970s, the Great Moderation, the financial crisis and Great Recession. All regimes are characterised by changes in the slope of the Phillips Curve as well as shifts in the relative dominance between the forward- and backward-looking terms.

This leads us to the second finding regarding the ongoing debate about which of the forward-looking and backward-looking component dominates inflation dynamics. The meta-Phillips shows that there are periods where the size of the forward-looking term may become bigger or smaller depending on the monetary policies in place. Nevertheless, the forward-looking term remains dominant throughout the sample as 
its coefficient exceeds that of the backward-looking term, validating a number of studies that suggest that expectations are important drivers of current inflation. 


\begin{tabular}{|c|c|}
\hline \multicolumn{2}{|c|}{$\begin{array}{l}\text { Table 1: OLS estimates of the determinants of the weighted average } \\
\text { coefficient on the backward-looking term in the meta-Phillips Curve }\end{array}$} \\
\hline Independent variables: & Dependent variable: $\bar{\gamma}_{b t}$ \\
\hline lagged inflation, $\pi_{t-1}$ & $\begin{array}{l}0.0187^{* * *} \\
(0.00416)\end{array}$ \\
\hline variance of inflation, $v_{t}$ & $\begin{array}{l}0.00699 * * * \\
(0.00185)\end{array}$ \\
\hline Burns regime & $\begin{array}{l}0.372^{* * *} \\
(0.0482)\end{array}$ \\
\hline Miller regime & $\begin{array}{l}0.326^{* * *} \\
(0.0521)\end{array}$ \\
\hline Volcker/early-Greenspan regime & $\begin{array}{l}-0.103^{* * *} \\
(0.0370)\end{array}$ \\
\hline mid-Greenspan regime & $\begin{array}{l}-0.176^{* * *} \\
(0.0361)\end{array}$ \\
\hline late-Greenspan regime & $\begin{array}{l}0.00621 \\
(0.0505) \\
\end{array}$ \\
\hline Bernanke regime & $\begin{array}{l}-0.200 * * * \\
(0.0437)\end{array}$ \\
\hline Yellen regime & $\begin{array}{l}0.101^{* *} \\
(0.0456)\end{array}$ \\
\hline constant & $\begin{array}{l}0.178^{* * *} \\
(0.0366)\end{array}$ \\
\hline Number of Observations and $R^{2}$ & 226 and 0.707 \\
\hline
\end{tabular}

Note:* ${ }^{* *}$ and ${ }^{* * *}$ denote significance at 10\%,5\% and 1\% levels. Robust standard errors reported in parenthesis. 


\begin{tabular}{|c|c|c|}
\hline Phase & Duration & Summary Overview \\
\hline \multirow[t]{3}{*}{$\begin{array}{l}1 \text { Martin/ } \\
\text { Bretton Woods I }\end{array}$} & \multirow[t]{3}{*}{$\begin{array}{c}1959 q 4- \\
1965 q 1\end{array}$} & $\begin{array}{l}\text { Bretton Woods system of fixed exchange rates. Strong } \\
\text { tightening policy when inflationary pressures in place. }\end{array}$ \\
\hline & & Mean Inflation $=1.27 \%$. Variance of Inflation $=0.57$ \\
\hline & & Average $\bar{\gamma}_{f t}, \bar{\gamma}_{b t}$ and $\bar{\lambda}_{t}: 0.637,0.363$ and 0.019 resp. \\
\hline \multirow[t]{3}{*}{$\begin{array}{l}2 \text { Martin/ } \\
\text { Bretton Woods II }\end{array}$} & \multirow[t]{3}{*}{$\begin{array}{c}1965 q 2- \\
1969 q 4\end{array}$} & $\begin{array}{l}\text { Rapid fiscal expansion. Perceptual shift in policy making. } \\
\text { Fed pursuing goals other than dollar and price stability. } \\
\text { De-anchoring of inflation expectations. }\end{array}$ \\
\hline & & Mean Inflation $=3.87 \%$. Variance of Inflation $=2.39$ \\
\hline & & Average $\bar{\gamma}_{f t}, \bar{\gamma}_{b t}$ and $\bar{\lambda}_{t}: 0.923,0.077$ and 0.040 resp. \\
\hline \multirow[t]{3}{*}{$\begin{array}{l}3 \text { early Burns/ } \\
\text { The Great Inflation }\end{array}$} & \multirow[t]{3}{*}{$\begin{array}{c}1970 q 1- \\
1973 q 4\end{array}$} & $\begin{array}{l}\text { Collapse of Bretton Woods system. High inflation episodes } \\
\text { due to uncontrolled budget deficits }\end{array}$ \\
\hline & & Mean Inflation $=5.19 \%$. Variance of Inflation $=5.21$ \\
\hline & & Average $\bar{\gamma}_{f t}, \bar{\gamma}_{b t}$ and $\bar{\lambda}_{t}: 0.467,0.533$ and 0.023 resp. \\
\hline \multirow{3}{*}{$\begin{array}{l}4 \text { Burns-Miller } \\
\text {-early Volcker/ } \\
\text { Energy Crisis }\end{array}$} & \multirow[t]{3}{*}{$\begin{array}{c}1974 q 1- \\
1982 q 1\end{array}$} & $\begin{array}{l}\text { Double digit inflation rates due to mounting energy prices } \\
\text { Policy emphasis on stabilising real economic activity. }\end{array}$ \\
\hline & & Mean Inflation $=9.14 \%$. Variance of Inflation $=10.93$ \\
\hline & & Average $\bar{\gamma}_{f t}, \bar{\gamma}_{b t}$ and $\bar{\lambda}_{t}: 0.274,0.726$ and 0.089 resp. \\
\hline \multirow[t]{3}{*}{$\begin{array}{l}5 \text { Volcker/ } \\
\text { The Big Disinflation }\end{array}$} & \multirow[t]{3}{*}{$\begin{array}{c}1982 q 2- \\
1986 q 2\end{array}$} & $\begin{array}{l}\text { Major shift in U.S. monetary policy. Proactive stance } \\
\text { towards controlling inflation. }\end{array}$ \\
\hline & & Mean Inflation $=3.40 \%$. Variance of Inflation $=4.61$ \\
\hline & & Average $\bar{\gamma}_{f t}, \bar{\gamma}_{b t}$ and $\bar{\lambda}_{t}: 0.845,0.155$ and 0.140 resp. \\
\hline
\end{tabular}


Table 2 (Continued): The phases the meta-Phillips Curve has undergone through and their key characteristics

\begin{tabular}{|c|c|c|}
\hline Phase & Duration & Summary Overview \\
\hline \multirow{3}{*}{$\begin{array}{l}6 \text { Early Greenspan/ } \\
\text { The Onset of } \\
\text { Great Moderation }\end{array}$} & \multirow{3}{*}{$\begin{array}{c}1986 q 3- \\
1992 q 1\end{array}$} & The Fed establishes strong anti-inflation credibility. \\
\hline & & Mean Inflation $=4.25 \%$. Variance of Inflation $=2.11$ \\
\hline & & Average $\bar{\gamma}_{f t}, \bar{\gamma}_{b t}$ and $\bar{\lambda}_{t}: 0.848,0.152$ and 0.046 resp. \\
\hline \multirow[t]{3}{*}{$\begin{array}{l}7 \text { mid-Greenspan I/ } \\
\text { The Dot.com Boom }\end{array}$} & \multirow[t]{3}{*}{$\begin{array}{c}1992 q 2- \\
1998 q 1\end{array}$} & $\begin{array}{l}\text { Demand management policy in response to deep } \\
\text { recession. Inflation tamed in the fear of overheating. }\end{array}$ \\
\hline & & Mean Inflation $=2.70 \%$. Variance of Inflation $=0.52$ \\
\hline & & Average $\bar{\gamma}_{f t}, \bar{\gamma}_{b t}$ and $\bar{\lambda}_{t}: 0.909,0.091$ and 0.049 resp. \\
\hline \multirow[t]{3}{*}{$\begin{array}{l}8 \text { mid-Greenspan II/ } \\
\text { Burst of the Bubble }\end{array}$} & \multirow[t]{3}{*}{$\begin{array}{c}1998 q 2- \\
2001 q 3\end{array}$} & $\begin{array}{l}\text { Outbreak of dot.com bubble. Unemployment and } \\
\text { business failures rising substantially triggering a recession. }\end{array}$ \\
\hline & & Mean Inflation $=2.54 \%$. Variance of Inflation $=1.04$ \\
\hline & & Average $\bar{\gamma}_{f t}, \bar{\gamma}_{b t}$ and $\bar{\lambda}_{t}: 0.788,0.212$ and 0.008 resp. \\
\hline \multirow{3}{*}{$\begin{array}{l}9 \text { Late-Greenspan/ } \\
\text { Early Bernake } \\
\text { Housing Boom }\end{array}$} & \multirow[t]{3}{*}{$\begin{array}{c}2001 q 4- \\
2008 q 4\end{array}$} & $\begin{array}{l}\text { Widespread mortgage lending. High consumer } \\
\text { indebtedness. Very volatile inflation. }\end{array}$ \\
\hline & & Mean Inflation $=2.61 \%$. Variance of Inflation $=8.31$ \\
\hline & & Average $\bar{\gamma}_{f t}, \bar{\gamma}_{b t}$ and $\bar{\lambda}_{t}: 0.886,0.114$ and 0.049 resp. \\
\hline \multirow{2}{*}{$\begin{array}{l}10 \text { Bernake/ } \\
\text { The Financial Crisis/ } \\
\text { The Great Recession }\end{array}$} & \multirow[t]{2}{*}{$\begin{array}{c}2009 q 1- \\
2014 q 4\end{array}$} & $\begin{array}{l}\text { High unemployment, business failures. } \\
\text { Fear of deflation. }\end{array}$ \\
\hline & & $\begin{array}{l}\text { Mean Inflation }=1.73 \% \text {. Variance of Inflation }=2.71 \\
\text { Average } \bar{\gamma}_{f t}, \bar{\gamma}_{b t} \text { and } \bar{\lambda}_{t}: 0.854,0.147 \text { and } 0.024 \text { resp. }\end{array}$ \\
\hline \multirow[t]{2}{*}{$\begin{array}{l}11 \text { Yellen/ } \\
\text { Slow Recovery }\end{array}$} & \multirow[t]{2}{*}{$\begin{array}{l}2015 q 1- \\
2016 q 1\end{array}$} & $\begin{array}{l}\text { Very low inflation and slow improvement } \\
\text { in the economy }\end{array}$ \\
\hline & & $\begin{array}{l}\text { Mean Inflation }=0.36 \% \text {. Variance of Inflation }=3.41 \\
\text { Average } \bar{\gamma}_{f t}, \bar{\gamma}_{b t} \text { and } \bar{\lambda}_{t}: 0.656,0.344 \text { and }-0.154 \text { resp. }\end{array}$ \\
\hline
\end{tabular}


Figure 1: The U.S. Inflation Rate (Annualised (log) change of Consumer Price Index)

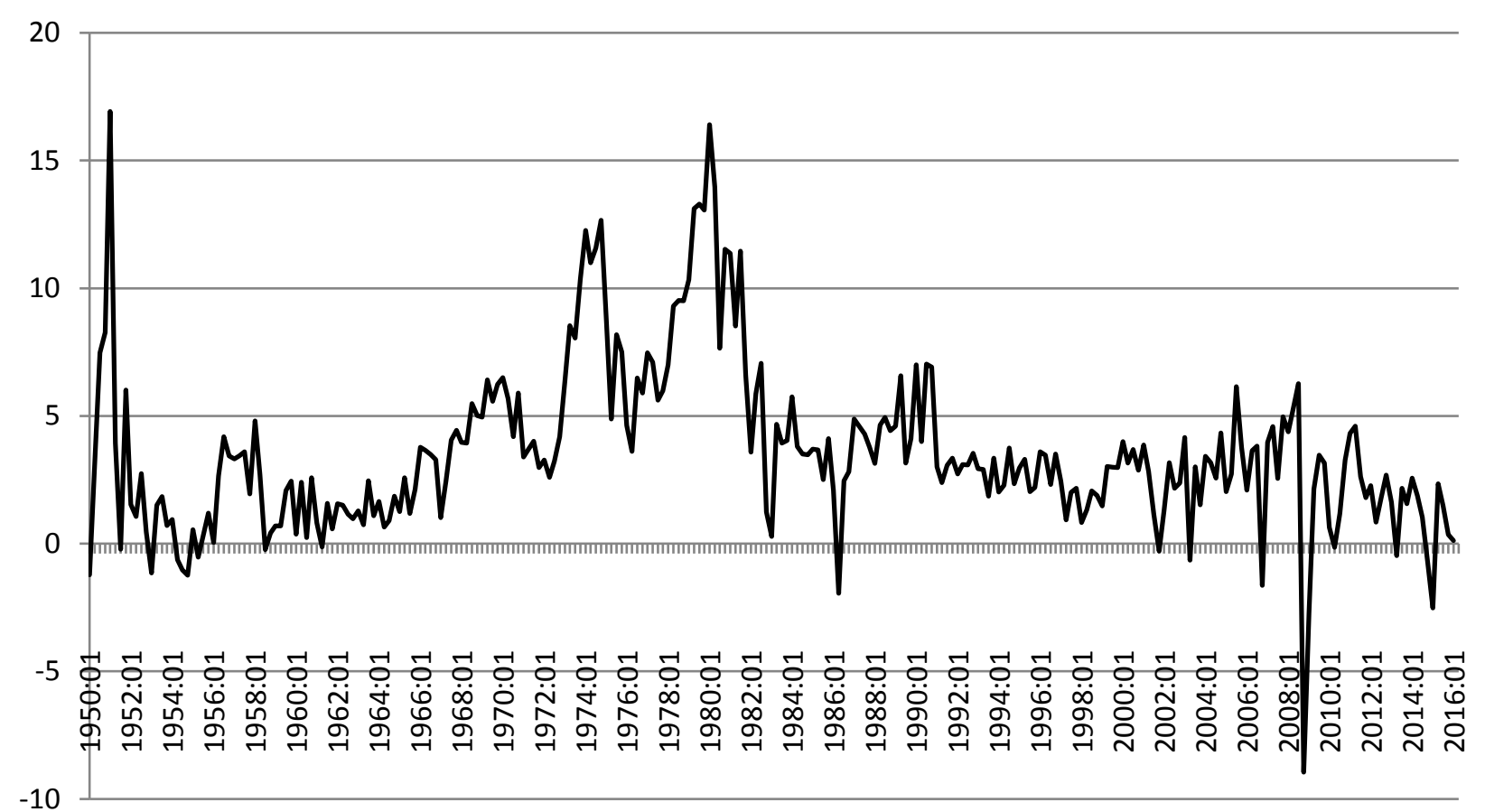

Figure 2a: The evolution of the weighted average sample size, $\bar{\jmath}_{t}$, over which a given hybrid NKPC holds.

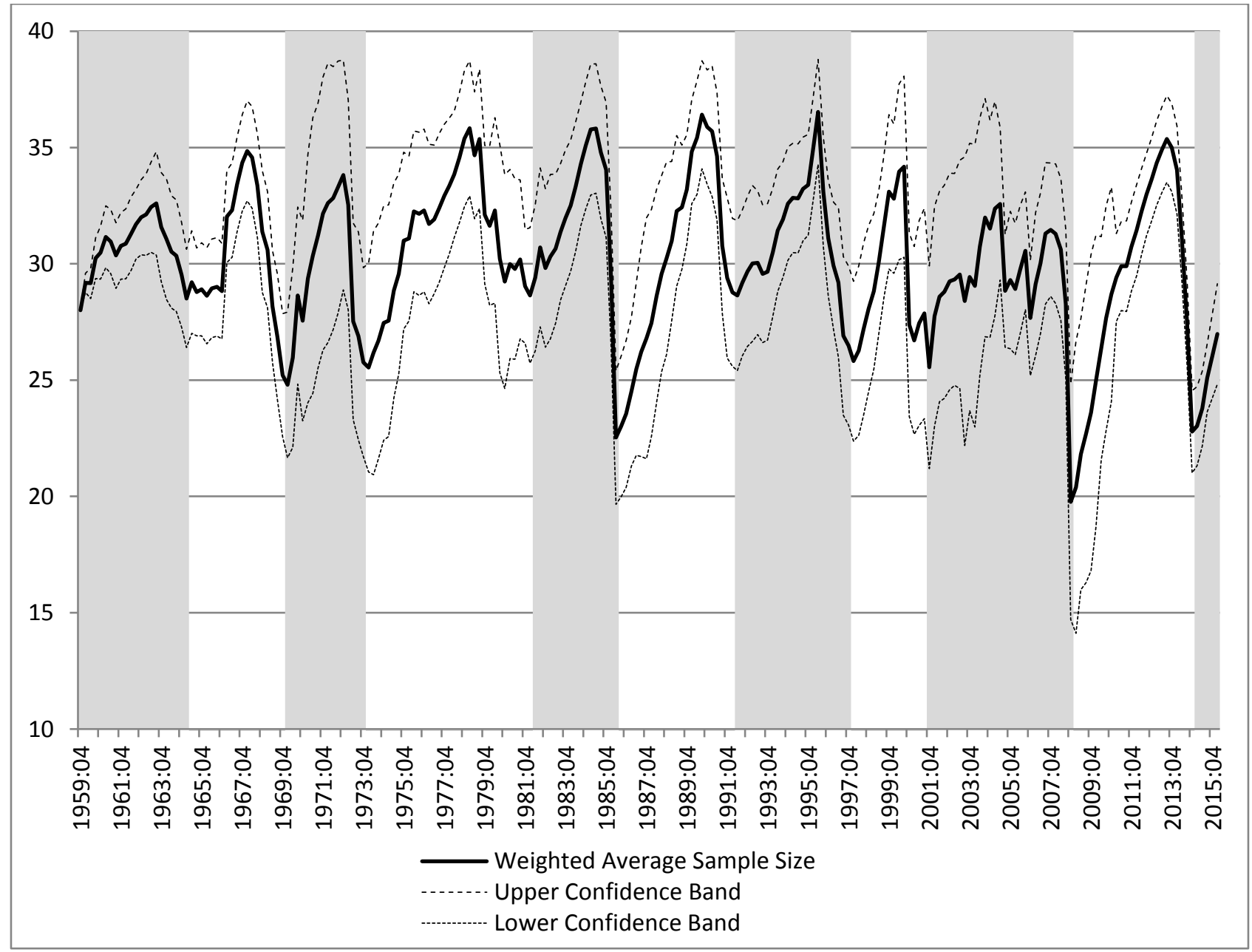


Figure $2 \mathrm{~b}$ : The evolution of the weighted average coefficient on the forward-looking term, $\bar{\gamma}_{\mathrm{ft}}$, in the meta-Phillips Curve

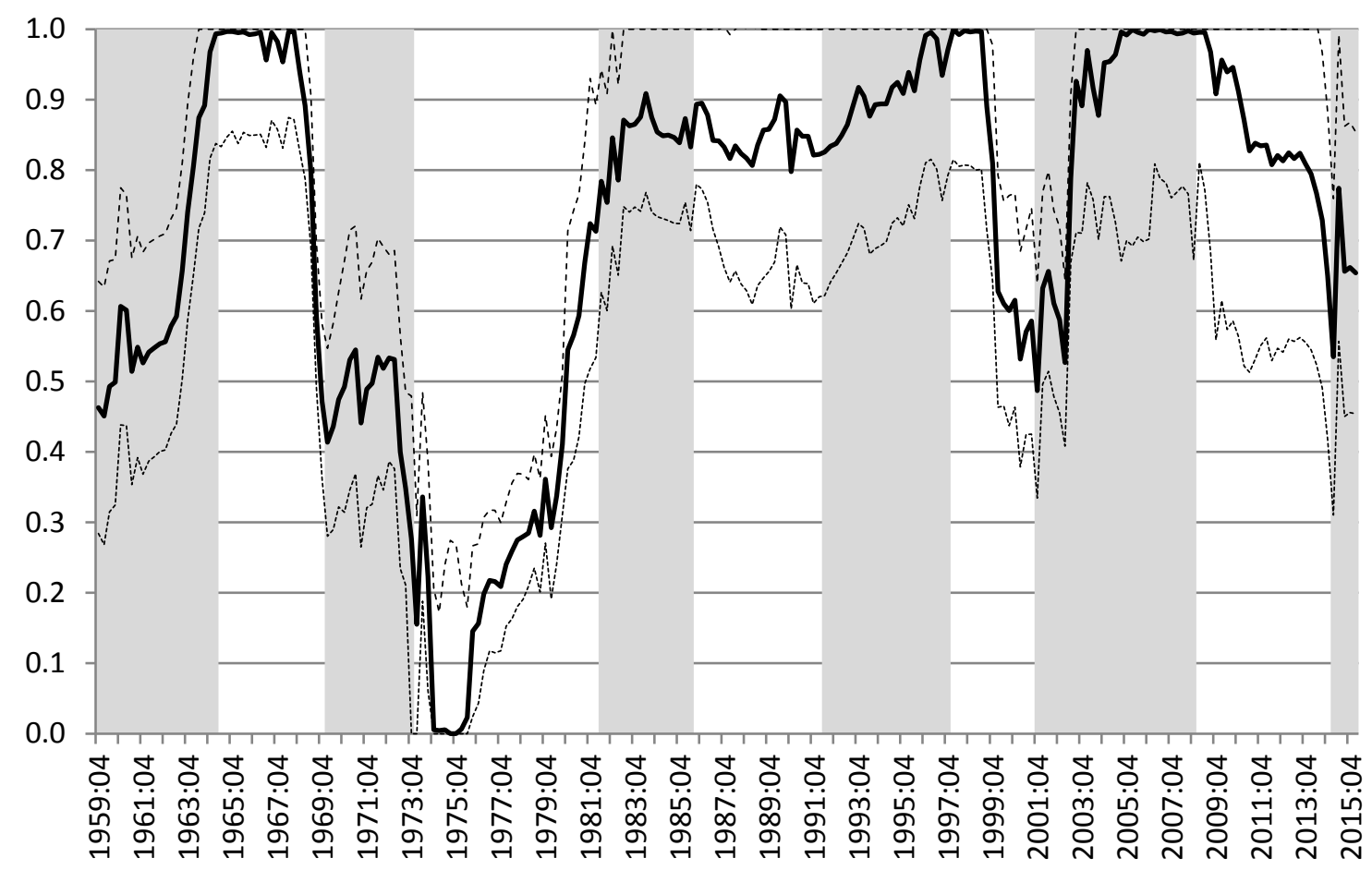

Weighted Average Coefficient on the Forward-Looking term Upper Confidence Band

Lower Confidence Band

Figure 2c: The evolution of the weighted average coefficient on the backward-looking term, $\bar{\gamma}_{b t}$, in the meta-Phillips Curve

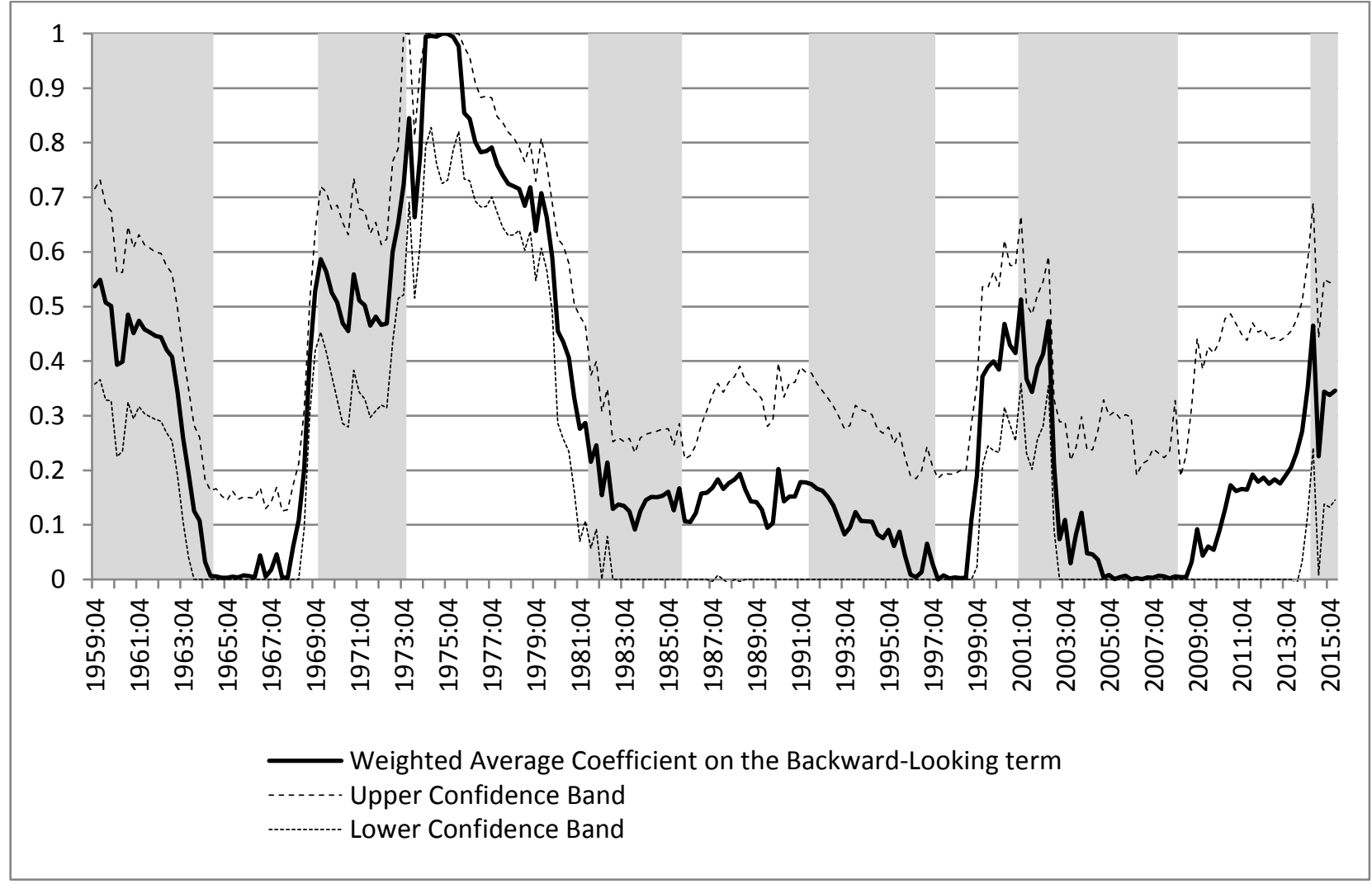


Figure $2 \mathrm{~d}$ : The evolution of the weighted average coefficient on the forcing term, $\bar{\lambda}_{t}$, in the meta-Phillips Curve

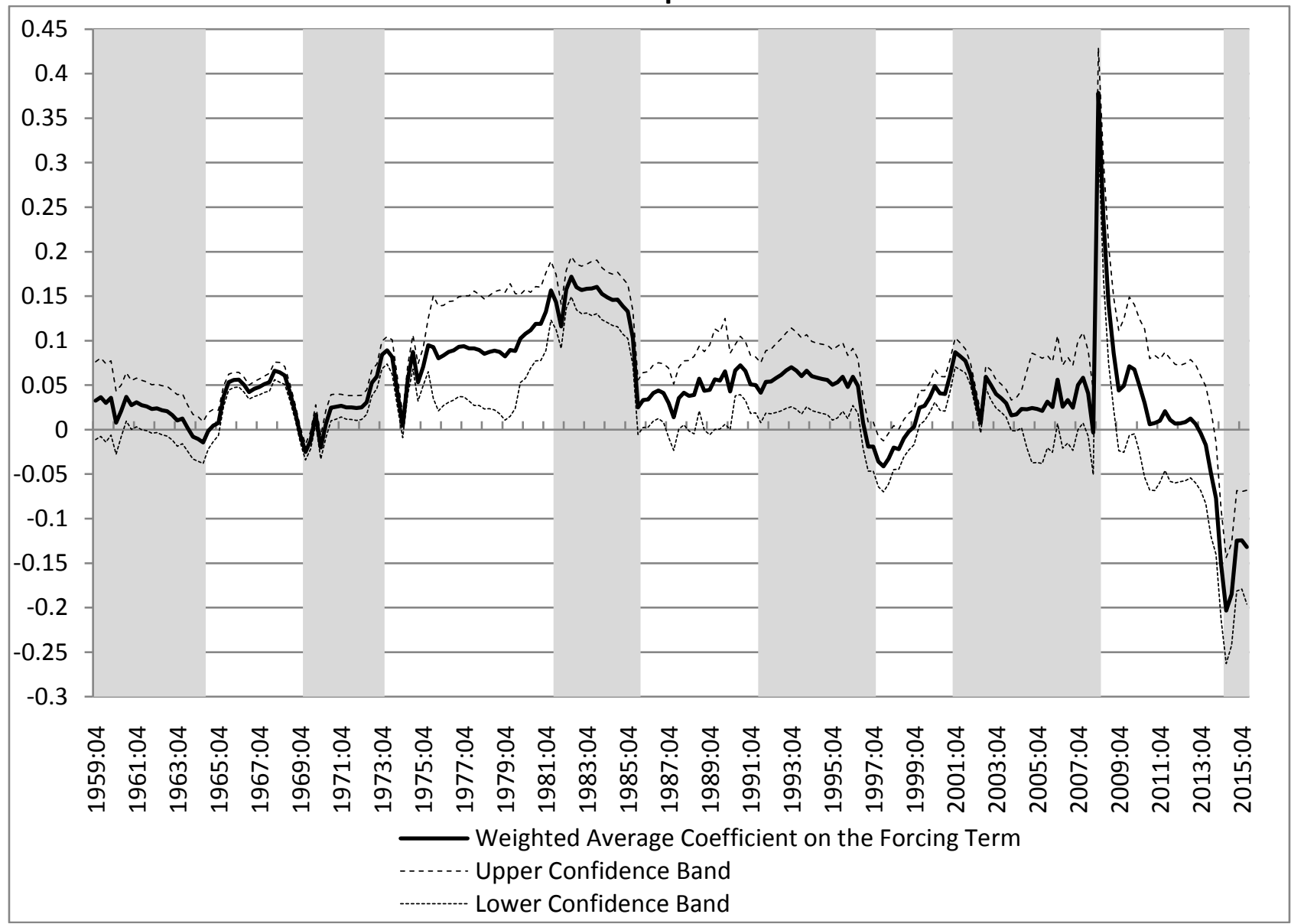

Figure 2e: The evolution of the $p$-value from the $t$ test of the null hypothesis that the average coefficient on the forward looking term is equal to the average coefficient on the backward looking term, against the alternative that the average coefficient on the forward looking term is larger than that on the backward looking term

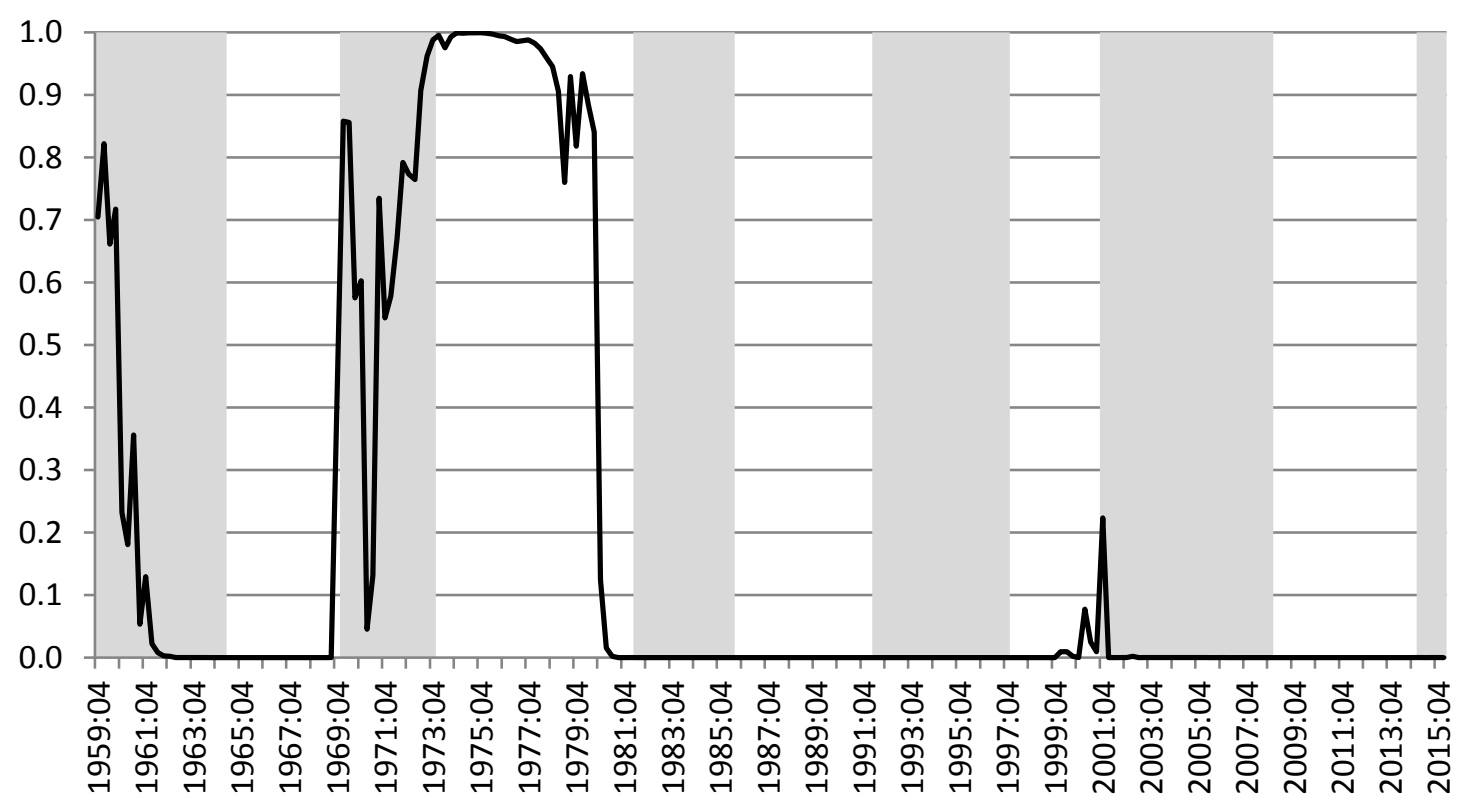




\section{References}

Ang, A., G. Bekaert, M. Wei (2007), "Do macro variables, asset markets, or surveys forecast inflation better?" Journal of Monetary Economics 54, pp.1163-1212.

Ascari, G., and A.M. Sbordone (2014), "The Macroeconomics of Trend Inflation," Journal of Economic Literature 52(3), pp.679-739.

Ball, L., N. G. Mankiw and D. Romer (1988), "The New Keynesian Economics and the Output-Inflation Trade-off," Brookings Papers on Economic Activity, 19, pp.1-82.

Bordo, M. D. and B. Eichengreen (2013), "Bretton Woods and the Great Inflation," In Bordo M.D. and A.Orphanides ed. The Great Inflation: The Rebirth of Modern Central Banking, NBER Book, pp.449-489.

Borio, C. E. V., and A. J. Filardo. (2007), "Globalisation and Inflation: New Cross-Country Evidence on the Global Determinants of Domestic Inflation," BIS Working Paper No. 227.

Clarida, R., J. Galí and M. Gertler (2000), "Monetary Policy Rules and Macro-

economic Stability: Evidence and Some Theory," Quarterly Journal of Economics, 115(1), pp.147-80.

Cogley, T. and T. J. Sargent (2001), "Evolving post-World War II U.S. inflation dynamics," In B. S. Bernanke and K. Rogoff (Eds.), NBER Macroeconomics Annual 2001, pp. 331 - 338. Boston, MA: National Bureau of Economic Research, Inc.

Davig T. (2016), "Phillips Curve Instability and Optimal Monetary Policy," Journal of Money, Credit and Banking, Vol. 48, Issue 1, pp. 233-246.

Draper, D. (1995), "Assessment and Propagation of Model Uncertainty," Journal of Royal Statistical Society Series B, 58, pp.45-97.

Erceg, C. J. and A.T. Levin (2003), "Imperfect credibility and inflation persis- 
tence," Journal of Monetary Economics, Elsevier, vol. 50(4), pp. 915-944.

Faust, J., J.H. Wright (2013),. "Forecasting inflation,". In Elliot, G., A. Timmermann (eds.), Handbook of Economic Forecasting, vol. 2, pp. 2-56. New York, NY: Elsevier.

Fuhrer, J. (1997), "The (Un)Importance of Forward-Looking Behavior in Price Specifications," Journal of Money, Credit, and Banking, 29, pp.338-350.

Fuhrer, J. (2011), "Inflation expectations and the evolution of U. S. inflation," Public Policy Brief.

Galí, J. and M. Gertler (1999), "Inflation Dynamics: A Structural Econometric Analysis," Journal of Monetary Economics, 44, pp.195-222.

Galí, J., M. Gertler and D. Lopez-Salido (2001), "European inflation dynamics," European Economic Review, 45(7), pp.1237-1270.

Galí, J., M. Gertler and D. Lopez-Salido (2005), "Robustness of Estimates of the Hybrid New Keynesian Phillips Curve," Journal of Monetary Economics, 52, pp.11071118.

Hoeting, J.A., D. Madigan, A.E. Raftery and C.T. Volinsky (1999), "Bayesian model averaging: A tutorial (with Discussion)," Statistical Science, 14, pp.382-401. Correction: vol. 15, pp.193-195.

Ihrig, J., S. B. Kamin, D. Lindner, and J. Marquez (2007), "Some Simple Tests of the Globalization and Inflation Hypothesis," International Finance Discussion Paper No. 891, Board of Governors of the Federal Reserve System.

Kim, C.J. and C.R. Nelson (1999), "Has the U.S. Economy Become More Stable? A Bayesian Approach Based on a Markov-Switching Model of the Business Cycle," Review of Economics and Statistics, 81, pp.608-16.

Kim, C.J., P. Manopimoke and C.R. Nelson (2014), "Trend Inflation and the Nature of Structural Breaks in the New Keynesian Phillips Curve," Journal of Money, 
Credit and Banking, Vol. 46, Issue 2-3, pp.253-266.

Kleibergen, F. and S. Mavroeidis (2009), "Weak instrument robust tests in GMM and the new Keynesian Phillips curve," Journal of Business and Economic Statistics, 27, pp.293-311.

Lee, K., Morley J. and Shields K. (2015), "The meta Taylor Rule," Journal of Money, Credit and Banking, Vol.47, Issue 1, pp.73-98.

Mavroeidis, S. (2005) "Identification issues in forward-looking models estimated by GMM with an application to the Phillips curve," Journal of Money, Credit and Banking, 37(3), pp.421-449.

Mavroeidis, S., M. Plagborg-Moller and J.H. Stock (2014), "Empirical Evidence on Inflation Expectations in the New Keyneian Phillips Curve," Journal of Economic Literature, Vol.52, No.1, pp.124-188.

Mazumder, S.(2010) "The New Keynesian Phillips Curve and the Cyclicality of Marginal Cost," Journal of Macroeconomics, 32, pp.747-765.

Melick, W. and G. Galati (2006), "The Evolving Inflation Process: An Overview." BIS Working Paper No. 196.

Mertens E. and J.M. Nason (2015), "Inflation and Professional Forecasts Dynamics: An evaluation of stickiness, persistence and volatility," Working paper, Centre for Applied Macroeconomic Analysis.

Mishkin, F.S. (2007), "Inflation Dynamics", International Finance, Vol.10, Issue 3, pp.317-334.

Montiel Olea, J. L. and C. Pflueger (2013), "A Robust Test for Weak Instruments." Journal of Business and Economic Statistics 31 (3) pp.358-369.

Musso, A., L., Stracca and D. van Dick (2009), "Instability and Nonlinearity in the Euro-Area Phillips Curve," International Journal of Central Banking, Vol. 5 No. 2, pp.181-212. 
Nason, J.M. and G.W. Smith (2008), "Identifying the New Keynesian Phillips curve,. Journal of Applied Econometrics 23(5), pp.525-551.

Neiss, K.S. and E. Nelson (2005), "Inflation Dynamics, Marginal Cost, and the Output Gap: Evidence from Three Countries," Journal of Money, Credit, and Banking, Vol.37, No.6, pp. 1019-1045.

Orphanides, A. and J.C. Williams (2012), "Monetary Policy mistakes and the Evolution of Inflation Expectations", a chapter in The Great Inflation, from National Bureau of Economic Research, Inc.

Roberts, J. M. (2006), "Monetary Policy and Inflation Dynamics." International Journal of Central Banking, September, pp.193-230.

Rudd, J. and K. Whelan (2005), "Does Labor's Share Drive Inflation?" Journal of Money, Credit, and Banking, 37, pp.297-312.

Rudd, J. and K. Whelan (2006), "Can Rational Expectations Sticky-Price Models Explain Inflation Dynamics?" American Economic Review, 96, 1, pp.303-320.

Rudd, J. and K. Whelan (2007), "Modelling Inflation Dynamics: A critical Review of Recent Research," Journal of Money, Credit and Banking, 39, s1, pp.155-170.

Russell, B, A. Banerjee, I. Malki and N. Ponomareva, (2010), "A Multiple Break Panel Approach To Estimating United States Phillips Curves," Dundee Discussion Papers in Economics 232, Economic Studies, University of Dundee.

Sbordone, A. (2002), "Prices and Unit Labor Costs: A New Test of Price Stickiness," Journal of Monetary Economics, 49(2), pp.265-292.

Sbordone, A. (2005), "Do Expected Future Marginal Costs Drive Inflation Dynamics?" Journal of Monetary Economics, 52(6), pp.1183-1197.

Staiger, J. and J. Stock (1987) "Instrumental variables regression with weak instruments," Econometrica, 65(3), pp.557-586.

Taylor, J. B. (2000), "Low Inflation, Pass-through, and the Pricing Power of 
Firms," European Economic Review, 44, pp.1389-408.

Zhang, C., D.R. Osborn and D.H. Kim (2008), "The New Keynesian Phillips Curve: From Sticky Inflation to Sticky Prices," Journal of Money, Credit and Banking, Vol. 40, No. 4, pp.667-699.

Zhang, C., D.R. Osborn and D.H. Kim (2009), "Observed Inflation Forecasts and the New Keynesian Phillips Curve," Oxford Bulletin of Economics and Statistics 71 (3), pp.375-398. 